\title{
The biosafety protocol slouches toward Montreal
}

\section{Russ Hoyle}

If there was ever a case of putting the cart before the horse, it is surely the out-of-whack relationship between the Convention on Biodiversity, signed with much fanfare at the 1992 Earth Summit in Rio de Janeiro, and the tedious diplomatic exercise known as the biosafety protocol. Conceived in part by Third World strategists as a diversion for industrialized nations and in part because there are no internationally accepted safety standards for trade in genetically engineered products, the quest for the biosafety grail has taken on a significance out of all proportion to its importance.

Indeed, as controversy swirled around larger issues like global warming at the fifth anniversary in June of the United Nations Conference on the Environment and Development (UNCED), the biodiversity protocol took on the dimensions of a high-priority "sideshow," as one US government official put it. At a second meeting this past May in Montreal of the "open-ended ad hoc working group of experts on biosafety" (which met for the first time in Arhus, Denmark last summer), the group of 77 (G-77) developing countries once more dominated the proceedings, forcing issues to the forefront that US and European negotiators considered peripheral or designed to scuttle propects for an accord.

Worse, it has become evident that antibiotechnology environmentalists, who may express uneasiness with the more extreme utterances of G-77 radicals (including one rhetorically gifted Ethiopian who reportedly declared in Montreal that genetic engineering could "resuscitate extinct organisms"), privately applaud such tactics as a way to curb trade in biotechnology products.

Many observers have come to believe that the overheated debate over the biosafety protocol is sapping resources that should be going "to conserve the biological wealth of the planet," as the Clinton administration declared upon finally signing the treaty a year after Rio in July 1993. "Other provisions of the treaty are going without attention because of the protocol," says one Washington insider.

Some have begun to wonder whether the UN-sponsored biosafety working group is an exercise in futility. Privately, at least, they worry whether US participation is worth the trouble, especially since Congress has yet to ratify the biodiversity treaty, relegating the US delegation to second-class status as a signatory, but not a party, to the convention. Yet even skeptics do not deny the critical importance to the US biotechnology industry of getting a reasonable agreement out of the current round of biosafety talks, scheduled to conclude in October of 1998.

And there is a growing realization, reportedly even among moderate G-77 countries in Latin America and elsewhere, that if the US withdrew from the biosafety talks, the outcome might be Draconian international biosafety standards that would effectively strangle the goose about to lay the golden egg. Any curb on international trade in biotechnology, coming at a time when US exports of biotechnology products to Europe and elsewhere are just moving into the pipeline, would be a stunning blow to the emerging US and European biotechnology industries.

For the Clinton administration, therefore, the importance of a sensible biosafety protocol is right up there with getting an accord on chemical weapons. The US effort is spearheaded by the Bureau of Oceans and International Environmental and Scientific Affairs of the State Department (Washington, DC), under the able and respected Eileen Claussen. Claussen, who announced her resignation last month for unknown reasons, has been instrumental in hammering out the US approach and coordinating policy with the US Department of Agriculture (Washington, DC), the US Food and Drug Administration (Rockville, $\mathrm{MD}$ ) and the Environmental Protection Agency (Washington, DC).

Earlier this month, the US, along with the other signatories and parties to the treaty, submitted draft proposals for the text of the biosafety protocol in preparation for the third meeting of the ad hoc biosafety working group in October in Montreal. At issue for US negotiators are the scope and application of the proposed biosafety document, including its "advanced informed agreement" provisions, under which importing countries would be assured prior knowledge of shipments of genetically engineered products that may pose risks to human health or the environment.

The battle lines will be drawn in Montreal between those, such as the Ethiopian and Indonesian negotiators, who are expected to declare that all genetically engineered products-referred to in diplomatic parlance variously as genetically modified organisms (GMOs) or living modifed organisms (LMOs)-are dangerous, and US, Japanese, and European representatives, who will propose provisions grounded in scientifically based assessments of risk, as represented in the existing range of US and European Community regulatory law.
The US proposals for the next Montreal round are expected to address two broad areas of the protocol: Its information-sharing components and the shape of its advanced informed agreement provisions. According to documents prepared for the Montreal meeting last May, US negotiators would like to see general information made available on genetically engineered products that would "serve to address issues of concern that competent authorities and interested others may have about biotechnology, LMOs, and LMO-based products."

Such information, including laws already on the books, scientific data about the production and use of LMOs, and existing regulatory risk assessments, should be readily exchanged and accessible through a centralized database or clearinghouse to "enable parties to make informed decsions related to biosafety."

On the complicated question of advance notification, the US contends simply that the importing country should "have an opportunity for informed decision making prior to importation" when "the LMO fits into a category of LMOs whos importation and intended use raise reasonable concerns regarding conservation and sustainable use of biodiversity." In other words, the advance informed agreement provision would kick in only when a genetically engineered organism is categorized as a risk for the importing country, according to "up-to-date scientific knowledge." The potential complications, from insufficient data in many importing countries to concerns about as-yet-unknown environmental or health risks, are legion.

Under the US framework, responses of importing countries could take a number of forms, including silence, which after a time would be considered assent. Again, the problems of definition, interpretation, and enforcement are endless.

In the end, the question is probably whether the US framework and those of the other industrialized countries will prove flexible enough to absorb modification. Some critics have already panned the US position, arguing that it may be a sound final product, but it leaves very little negotiating room. Its defenders counter that it is a position of good sense and strength that is practically workable that they can advocate forcefully. "We think it's doable," says an official close to the talks. Such optimism, however, almost certainly depends on a silent shift within the ranks of the G-77 in favor of seriously considering the US position. So far, it hasn't happened. 